\section{ANXIETY AND ATTRIBUTIONAL RESPONSES OF COMPETITIVE SQUASH PLAYERS}

\author{
F. H. Sanderson and J. Gilchrist \\ Dept. of Sport and Recreation Studies, \\ Liverpool Polytechnic
}

A tendency has been noted, mainly in laboratory contrived situations, that individuals attribute failure at a task to external causes - powerful opponents, luck, and success to internal causes - ability and effort le.g. Miller, 1976). This has been explained in terms of a selfserving bias in which the individual attempts to protect his self-esteem. However, several recent field studies have found conflicting results, particularly with respect to the association between failure and external attribution (e.g. Scanlan and Passer, 1980). The present study was designed to investigate the extent of self-serving bias in the individual sport context, where little previous research has been undertaken.

Twenty-six male North-West league squash players acted as subjects, and were asked to attribute causality for competitive performance outcomes to nine selected internal factors and nine selected external factors. They were also required to complete pre- and post-match state anxiety questionnaires. The causality questionnaire was administered $30 \mathrm{~min}$ after the match and the anxiety questionnaire immediately prior and subsequent to the match.

Main hypotheses were that pre-match anxiety affects performance adversely, post-performance anxiety levels rise after failure and fall after success, and winners attribute more internally than losers. No relationship was found between pre-match anxiety and performance. Analysis of post-match anxiety scores revealed that winners' anxiety fell $(p<.001)$ and losers' anxiety rose significantly $(p<.05)$. Although winners were found to attribute more internally $(p<.001)$ and less externally $(p<.001)$ than losers, the latter still assessed internal attributes to be the most important determinants of match outcome. It was argued that social norms/ constraints associated with squash tend to limit the acceptability of external attributions.

\section{References}

Miller, D. T., 1976 "Ego involvement and attributions for success and failure". Journal of Personality and Social Psychology 34: 901-906.

Scanlon, T. K. and Passer, M. W., 1980 "Self-serving biases in the competitive sport setting: an attributional dilemma". Journal of Sport Psychology 2: 124-136.

\section{CIRCADIAN VARIATION IN VENTILATORY AND METABOLIC ADAPTATIONS TO SUBMAXIMAL EXERCISE}

$$
\text { T. Reilly, }
$$

\section{Dept. of Sports and Recreation Studies, Liverpool Polytechnic}

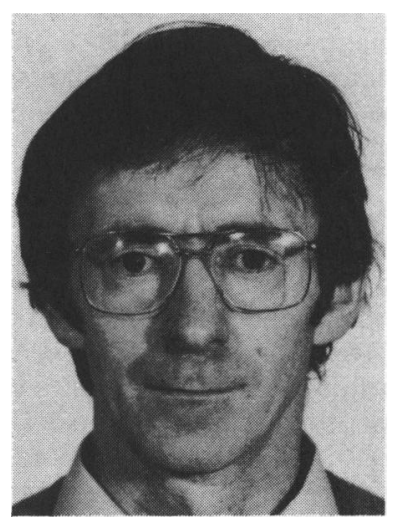

T. Reilly

Circadian ihythms are extensively documented for resting physiological functions, ventilatory and metabolic cycles following the body temperature curve with an afternoon peak (Minors and Waterhouse, 1981). Such ihythms could have implications for training as increasing internal resistance to muscle contraction with lowered temperatures would raise the energy demand and adversely affect mechanical efficiency. Additionally, there is some theoretical foundation but no experimental evidence for the claim that attainment of physiological equilibria after onset of exercise is retarded at night. This study was undertaken to determine whether resting hythms persisted in steady-rate conditions and whether the rate of acute response to exercise and the mechanical efficiency fluctuated with the time of day.

A longitudinal study $(n=37)$ over 16 weeks was employed using a single-subject design for effective control of major zeitgebers in the nychthemeron. A male athlete performed 2 consecutive 5 min cycling bouts of 80 and $150 \mathrm{~W}$ at 6 times of the solar day. Preexercise $10 \mathrm{~min}$ rest measures were obtained for rectal temperature $(\mathrm{Tr})$, pulse rate $(\mathrm{fH})$, oxygen uptake $\left(\mathrm{VO}_{2}\right)$ and minute ventilation (VE). $\mathrm{VO}_{2}$ and $V E$ were measured continuously during exercise by an automated on-line system: gross, net and delta "muscular efficiency" were calculated according to Donovan and Brooks (1977). The rate of adaptation was assessed by reference to the fifth minute value for each load.

Cosinor analysis established significant resting periodicities in $\mathrm{Tr}, \mathrm{fH}, \mathrm{VO}_{2}$ and $\mathrm{VE}(\mathrm{p}<0.005): \mathrm{fH}$ led the others in phase, $\mathrm{VE}$ also leading $\mathrm{VO}_{2}$ and $\mathrm{Tr}$ signifi- 
cantly ( $p<0.05)$. Acrophases were all between 15:30 and $17: 45$, VE manifesting the strongest amplitude. A circadian oscillation was observed in $\mathrm{VO}_{2}$ at $150 \mathrm{~W}$ when values were uncorrected for body weight and resting levels, the acrophase occurring at 14:40 $(p<0.05)$. Gross efficiency was $18( \pm S D=0.8) \%$ and 20.9 ( $\pm \mathrm{SD}=0.7) \%$, net efficiency was $24.5( \pm \mathrm{SD}=0.5$ ) and 25.2 ( $\pm \mathrm{SD}=0.2) \%$ at the light and heavier loads while delta efficiency was $26( \pm S D=2.2) \%$. None of the efficiency calculations varied with time of day, the significant increase in gross efficiency with work increment being a computational artefact.

$\mathrm{VO}_{2}$ responses attained steady-rate in the second minute of each load irrespective of time of day. Ventilation values at each load failed to stabilise until the fourth minute, this adaptation rate being independent of time of day. The circadian rhythm in VE persisted in phase and amplitude at both loads, delta values over rest being similar for the 6 time points. The ventilatory equivalent ( $\left.\mathrm{VE} / \mathrm{NO}_{2}\right)$ during steady-rate was 22.9 $( \pm S D=1.3)$ : the value was unaffected by the work intensities used but varied with time of day at each load $(p<0.05)$.

\section{LIGHT EXERCISE}

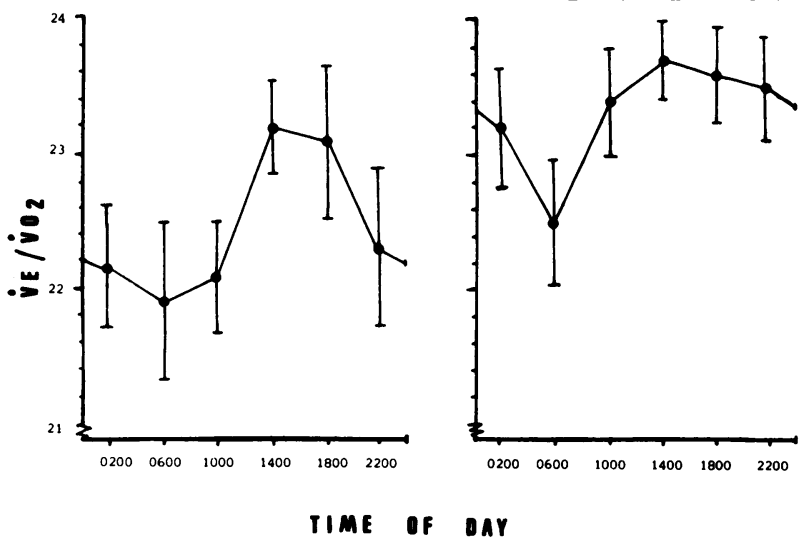

Fig. 1. Ventilatory equivalent for 6 times of day at light and medium intensity exercise.

Results suggest that the periodicity in ventilation is partially independent of the oscillator linking body temperature and metabolic rate. Its persistence in submaximal exercise has only minor repercussions for cellular respiration. It is concluded that circadian rhythms in $\mathrm{VO}_{2}$ are relatively unimportant in affecting the rate and level of adaptation to moderate work loads: the more robust VE cycle contributes to the greater discomfort associated with nocturnal exercise without any al teration in muscular efficiency.

\section{TABLE I}

Mean percentage of 5 th minute value for each minute at light and medium exercise intensity.

\begin{tabular}{lcccc} 
& \multicolumn{2}{c}{ Light Exercise } & \multicolumn{2}{c}{ Medium } \\
& $\mathrm{VO}_{2}$ & $\mathrm{VE}$ & $\mathrm{VO}_{2}$ & Exercise \\
& & & & \\
1st minute & 73.1 & 76.4 & 81.1 & 79.2 \\
2nd minute & 101.9 & 93.1 & 98.9 & 95.9 \\
3rd minute & 100.8 & 96.2 & 98.9 & 97.8 \\
4th minute & 99.3 & 98.2 & 98.7 & 98.5
\end{tabular}

\section{References}

Donovan, C. M. and Brooks, G. A., 1977 "Muscular efficiency during steady-rate exercise. II. Effects of walking speed and work rate." J.Appl.Physiol. 43: 431-435.

Minors, D. G. and Waterhouse, J. M., 1981. Circadian rhythms and the human. John Wright: Bristol.

\section{ESTIMATION OF TOTAL BODY FAT IN RUGBY UNION FORWARDS FROM MEASUREMENTS OF HUMAN BODY DENSITY AND SUBCUTANEOUS TISSUE THICKNESSES \\ W. Bell \\ Dept. of Physical Education, Institute of Higher Education, Cardiff}

The tissue composition of the body is an important characteristic of the practicing athlete and games player. In the United Kingdom there are a number of suitable equations for the estimation of TBF in normal individuals, but because of the differences between athletic and non-athletic groups these equations are seldom appropriate for sportsmen and women. It is desirable that specific equations be formulated for particular sporting groups. The present study, therefore, provides prediction equations to estimate TBF in rugby union forwards.

Measurements of human body density were determined by hydrostatic weighing. Ten measurements were taken, the mean of the last three trials being used as the final underwater weight. A correction was made for residual volume using the closed circuit three-breath nitrogen dilution technique. Four skinfolds were taken on the left hand side of the body at the biceps, triceps, subscapular and suprailiac sites. Linear regression equations were determined to estimate body density from single skinfolds and from the sum of the four skinfold measurements.

Body density was used as the dependent variable and skinfold thickness as the independent variable. Because 